\title{
INVESTIGATION OF FACTORS INFLUENCING THE EFFICIENCY OF RAILWAYS IN TERMS OF SAFETY AT LEVEL CROSSINGS
}

\author{
INARA WATSON, AMER ALI \& ALI BAYYATI* \\ School of the Built Environment and Architecture, London South Bank University, \\ United Kingdom
}

\section{ABSTRACT}

Road traffic accidents are in the top ten of all deaths worldwide. Regarding railways, in the EU there is one person killed or seriously injured every day in serious accidents involving level crossings (LCs). The number of accidents is almost unchanged in the last ten years despite the huge efforts that railways have made. There is a need to look at the factors that contributed to the occurrence of accidents at LCs beyond the drivers and pedestrian behavior or technical issues. The reported research investigates the efficiency of railways in terms of accident risk at LCs in 24 countries of the EU. It evaluates the efficiency of railways by applying the Data Envelopment Analysis (DEA) method and identifying the factors that influence the efficiency score of railways in terms of accident risk using the IBM SPSS. The results show that GDP per capita and density of population in the selected countries have a strong influence on the efficiency of railways. The expected outcome of this research may contribute to better understanding of the factors that influence the efficiency score of railways in term of accident risk at LCs and develop preventative measures.

Keywords: level crossings, accidents, efficiency score and influencing factors.

\section{INTRODUCTION}

A Level Crossing (LC) is a point where road and rail infrastructure intersect. As stated by United Nations Economic Commission for Europe (UNECE) in 1968, trains have priority and road users and pedestrians must give way to trains. There are many different types of LCs, but all of them must ensure the safety for road and rail uses. LCs are responsible for the second highest number of accidents on railways and there is a need to look for new solutions to reduce the number of accidents that would be economically acceptable. Apart from safety issues, LCs affect the speed of the trains and this reduces the capacity of lines and increases travel time [1]. They also cause disruption for road users and generates congestion [2]. In the future, the number of trains and cars will only increase. The best solution would be to remove LCs. This will improve the safety for road and railway users, reduce noise and air pollution from stopping and starting cars. Very often it is economically inappropriate. Railway authorities around the world are looking for cost-effective technological solutions that may improve the safety at LCs. To do so, there is a need to fully investigate factors that can influence the safety at LCs. Some of these did not get enough attention in the past, such as the population density, number of cars per 1000 inhabitants, GDP per capita, median age and the number of road accidents in selected countries. Whilst technology can help improve safety, but such safety can also be improved by educating the public and by means of law enforcement.

\section{METHODOLOGY}

The combination of several methods and different approaches may identify the major factors that influence the number of accidents at LCs. The approach is mainly qualitative and descriptive, supported by Data Envelopment Analysis (DEA) and IBM SPSS analyses of

\footnotetext{
*ORCID: http://orcid.org/0000-0002-4976-3776
} 
existing empirical evidence. In this research, aggregate statistics, which include numerical and non-numerical data, are collected and summarised to help having a clearer picture of safety at LCs. The DEA is used to evaluate the efficiency of performance of selected railways. For this, railways in 24 countries in Europe are studied and five years of data is analysed. Inefficient railways are made efficient through the proportional reduction of inputs. In this research, inputs are the number of accidents at LCs.

DEA calculates the lowest range of accidents for the given volume of passenger-km and thousands of tons of goods transported by railways in selected countries during the period 2012-2016. The model finds targets for the reduction of the number of accidents at LCs that need to be achieved by every country to be classified as an efficient railway. The outputs, number of passenger-km and tonnes-km proportions are kept constant. The selection of data is influenced by the data availability and difficulties in obtaining data. All data is derived from the UIC website, UNICE, Eurostat and annual reports and scientific publications.

\section{TYPES OF LEVEL CROSSINGS}

The type of LC depends on factors such as traffic, volume of trains and vehicles, types of use, area of location etc. LCs can be passive or active. Most LCs around the world are passive. In Australia it is $67 \%$ of the total number of LCs and 75\% in the USA [3]. In 2011, in the UK, $75 \%$ of all LCs were passive but in Belgium only 15\% [4]. In 2010, in the EU there were around 123,000 level crossings, $47 \%$ of them were passive and $53 \%$ active but only $28 \%$ provided barrier protection for road users. In Europe there are approximately five level crossings for every $10 \mathrm{~km}$ of line [5].

The passive LC is equipped with only warning signs such as "STOP" and a "ST ANDREW's CROSS", and road markings. It is up to the user to decide when it is safe to cross the line. There are 2,814 of this type of LC in the UK [6]. Regarding the active LC, in addition to warning signs and road markings, the LC is equipped with warning systems that warn road uses about approaching trains. The warning systems consist of flashing lights and sounds and some have a barrier between the train and road users that close when the train approaches. The effectiveness of any automatic warning system depends on a good visibility of the warning signals. The safest type of crossings is the grade separation LC that separates the rail and road traffic by building an overpass or underpass. This type of crossing is the most expensive option, but it is not always economically viable.

It is clear that, the higher the number of level crossings the higher possibility of accidents. The UK has $41 \mathrm{LCs}$ per $100 \mathrm{~km}$ and that is slightly less than the average in the EU which stands at $50 \mathrm{LCs}$ per $100 \mathrm{~km}$ of railway line [7]. The highest density of LCs is approximately 75 LCs per $100 \mathrm{~km}$ of railway line which belongs to Sweden, Austria, the Czech Republic, but the Netherlands, Bulgaria and Spain have the lowest density of LCs per km of line and it is less than $25 \mathrm{LCs}$ per $100 \mathrm{~km}$ [8].

\section{LC ACCIDENTS AND TYPES OF USERS INVOLVED}

Approximately 25,700 people died in 2014 on the roads in the EU [9] whilst the railways had 2213 serious accidents and there were a total of 1928 people that had fatal or serious injuries. Moving rolling stock caused 1196 accidents and 638 accidents happened at level crossings [10]. The accidents and fatalities on railways cost the society in Europe more than $€ 1.4$ billion every year [11]. This cost is negatively affecting the economic sustainability of railways. There are two types of LC accidents, namely, collision of road vehicles with trains, and collision of road vehicles with LC devices. The latter is a huge problem for railways around the world. There was an increase in the number of drivers and pedestrians in UK that had near-miss accidents with trains from 140 drivers in 2009 to 161 in 2010 whilst the number of pedestrians 
for the same period rose from 270 to 297 . These figures show that people ignore the warning signals at LCs [12]. Local drivers in rural areas are often overconfident and do not recognise that the risk of rural crossings is high and that may lead to accidents. Drivers do not look carefully for trains before crossing. There are hundreds of near-miss accidents every year [4].

On average, one person was killed or seriously injured every day at LCs in Europe. It was found that approximately $70 \%$ of all LC accidents occur approximately within $10 \mathrm{~km}$ of a car driver's home [14]. Fig. 1 shows the types of users involved in accidents at LCs in the EU.

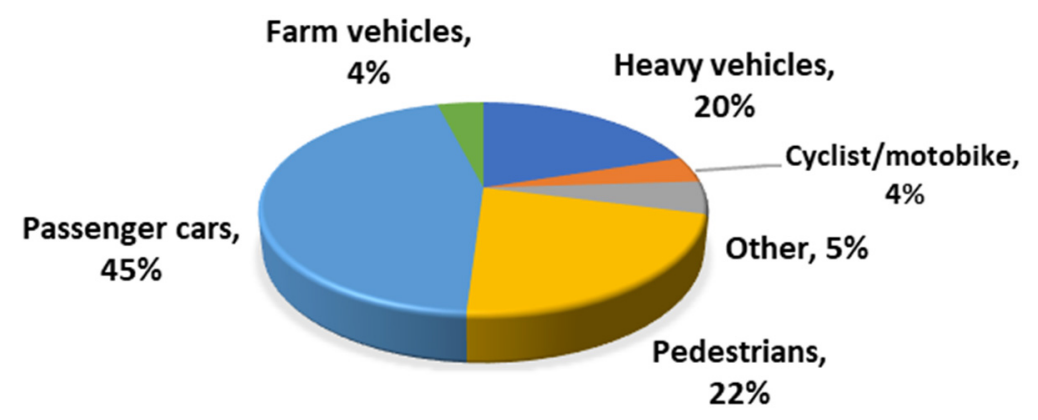

Figure 1: Types of the LC users involved in accidents in the EU. (Source: ERA, 2012b.)

Increased speeds of trains and vehicles on roads require greater sight distance for deciding whether to enter a LC or not. One of the main causes of crashes at LCs where there is a lack of barriers, is the behaviour of drivers who fail to judge correctly the speed and distance of approaching trains [3]. In 1996, the Transport Research Laboratory (UK) identified two categories of drivers that are most likely to be involved in accidents at LCs: drivers who believe that they have enough time to cross before train arrives, and do not stop or cannot stop because they are too close to the "stop line" when the amber light starts to flash, and drivers who are distracted or careless of the signals. Introduction of barriers at LCs can stop these types of drivers from being involved in accidents. Drivers are more likely to see the barrier as it is in front of their field of vision and will stop [6]. Drivers sometimes are trying to weave around the close half-barriers at LCs. These types of accidents are the second most common after over speeding when approaching the LC [15], [16]. To prevent this type of accident, two half-barriers can be replaced by two full barriers or four half-barriers. In the EU in 2016, 25,500 people died in road accidents, 296 of them at LCs. It is approximately $30 \%$ of all railway fatalities and $1.2 \%$ of all road fatalities [11]. Fig. 2 shows the number of accidents and fatalities at LC in EU 2009-2011.

The accidents and fatalities at LCs not only damage the safety and reputation of the rail industry, but also has a huge cost to society. In 2010 in Europe, this cost was estimated at $€ 350$ million [5]. Fig. 2 also shows the decreasing number of accidents and fatalities at LCs in EU between 2009 and 2011.

Approximately, three-quarters of all accidents at LCs involved pedestrians and fatality rate is higher for pedestrians than for car occupants. For example, in Australia $66 \%$ of all fatalities (excluding suicides) were pedestrians [17]. They are at greater risk than other road users. It was found that road users behave differently with respect to different warning systems at LCs. The LC with a passive warning system has higher accident rates, but a LC with barriers and flashing light has a lower accident rate [4], [18]-[20]. 


\section{NUMBER OF ACCIDENTS AND FATALITIES AT LEVEL CROSSINGS IN EU}

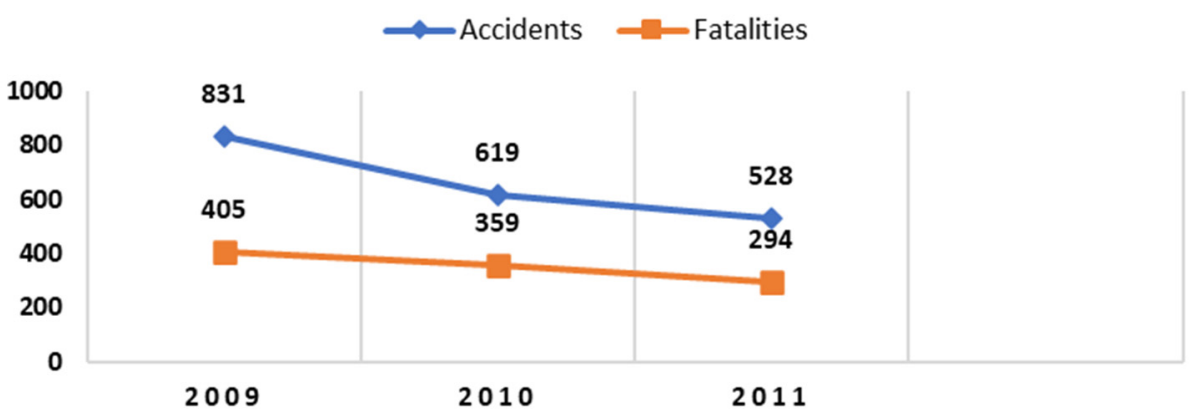

Figure 2: Number of accidents and fatalities at LCs in the EU. (Source: EC, 2017.)

The major reasons of accidents at LCs are distraction of car drivers or pedestrians, impatience, and the high speed of vehicles approaching LCs [15]. These users' behaviour is the reason for accidents in $95 \%$ of cases [7]. Weather conditions, using headphones, mobile phones, vehicle music systems and many more disruptions can affect the ability to hear approaching trains. Also, modern trains have a substantially reduced noise level. From time to time people cross the LC straight after the train passes whilst the alarms are still operating, but there can be another train that is coming from the opposite direction. Referring to the European Railway Agency, in 2013, UK's fatality risk at LCs was the lowest in the EU. The highest fatality risk at level crossings was in Greece which was more than 28 times higher than that of the UK and was the highest fatality rate in the EU [21].

Despite all efforts, the number of accidents at LCs in the EU in the last ten years remained stable [4]. Moreover, it has been found that the number of drivers and pedestrians who disobey the LC signals are increasing [12]. The LC represents a big operational risk and the most logical thing would be for all of them to close, but it can restrict mobility in some places whilst building grade separation crossings is not always possible in built up areas in countries such as the Netherlands or Japan. Building bridges or underpasses is very expensive, approximately $€ 5-10$ million in Europe. For example, replacing the LC at Elsenham, (UK) with a bridge it costed around $£ 4$ million [22].

\section{INPUT ORIENTED DEA APPROACH}

The DEA analysis has been acknowledged before as benchmarking the performance of Decision-Making Units (DMU) and found the best practice. The efficiency of DMUs depends on their distance to the frontier. This methodology uses the ratios between outputs and inputs and compares all units and their relative efficiency with respect to the best performing unit.

One advantage of applying the DEA is that it can operate with multiple inputs and outputs and is not needed to clarify their importance. Other advantages are that it is suitable for small samples and has a small run time [23]. The DEA compares each railway with all other railways and identifies railways that are operating inefficiently and finds the target values of output and input for inefficient railways. The DEA technical efficiency and service effectiveness study for railways was carried out by [24].

The CCR model is named after its developers Charnes, Cooper and Rhodes (1978) and BCC model is named after Banker, Charnes and Cooper (1984). The CCR model is based on 
an assumption of constant returns-to-scale (CRS). For this research, the input oriented CCR model has been applied. Input oriented model means that outputs will be kept constant, but inputs must be reduced to reach the frontier line. For this research one input was selected that is the number of accidents at LC and two outputs were selected, that are the thousand tonnes of goods transported by railway and millions of passenger-km. The efficiency is defined as the ratio of the output to input, and this ratio must be equal or less than 1 . If the ratio is equal to 1 , it points to the most efficient DMUs. Table 1 shows the efficiency of CRS input oriented CMI DEA for selected countries in the period 2012-2016.

Table 1: Efficiency of CRS input oriented CMI DEA for selected countries 2012-2016.

\begin{tabular}{|l|c|c|c|c|c|c|}
\hline Country & 2012 & 2013 & 2014 & 2015 & 2016 & Mean \\
\hline AT & 23.97 & 10.88 & 19.79 & 4.6 & 8.66 & 13.58 \\
\hline BG & 5.41 & 4.46 & 3.81 & 3.36 & 4.31 & 4.27 \\
\hline HR & 4.23 & 2.05 & 5.3 & 1.08 & 4.2 & 3.37 \\
\hline CZ & 14.4 & 8.88 & 10 & 5.02 & 7.22 & 9.1 \\
\hline DK & 19.71 & 16.66 & 15.1 & 9.89 & 6.47 & 13.57 \\
\hline EE & 85.39 & 39.12 & 37.01 & 14.47 & 14.95 & 38.19 \\
\hline FI & 28.06 & 56.9 & 56.61 & 5.75 & 11.84 & 31.94 \\
\hline FR & 38.38 & 32.79 & 23.05 & 6.69 & 20.58 & 24.3 \\
\hline DE & 43.15 & 46.7 & 31.02 & 9.48 & 16.74 & 29.42 \\
\hline GR & 2.17 & 2.68 & 1.48 & 0.29 & 12.18 & 3.76 \\
\hline HU & 8.78 & 6.41 & 8.84 & 2.81 & 5.27 & 6.42 \\
\hline IT & 38.41 & 49.83 & 44.76 & 11.91 & 40.65 & 37.11 \\
\hline LV & 72.32 & 100 & 87.25 & 19.16 & 46.99 & 65.14 \\
\hline LT & 94.28 & 34.41 & 33.31 & 33.09 & 20.07 & 43.03 \\
\hline NL & 23.95 & 15.47 & 25.7 & 5.75 & 37.05 & 21.58 \\
\hline PL & 22.72 & 11.18 & 20.5 & 4.93 & 7.54 & 13.37 \\
\hline PT & 7.12 & 4.86 & 7.69 & 3.28 & 5.45 & 5.68 \\
\hline RO & 5.27 & 2.84 & 3.41 & 3.26 & 3.53 & 3.66 \\
\hline SK & 11.3 & 10.22 & 10.76 & 3.76 & 8.76 & 8.96 \\
\hline SI & 15.11 & 5.12 & 11.01 & 2.83 & 6.09 & 8.03 \\
\hline ES & 50.15 & 42.01 & 31.05 & 9.77 & 24.65 & 31.53 \\
\hline SE & 36.94 & 20.19 & 27.75 & 12.21 & 28.42 & 25.1 \\
\hline UK & 100 & 100 & 100 & 100 & 86.87 & 97.37 \\
\hline CH & 82.2 & 85.7 & 100 & 34.13 & 100 & 80.41 \\
\hline Mean & 34.73 & 29.56 & 29.82 & 12.81 & 22.02 & 25.79 \\
\hline
\end{tabular}

The technical efficiency of railways shows that the efficiency of railways in terms of accident risk per million passenger-km and thousand tonnes of goods transported by railways in selected countries. The highest efficiency scores for the selected period 2012-2016 was UK and $\mathrm{CH}, 97.37 \%$ and $80.41 \%$ respectively. The railway in the UK was efficient 4 out 5 of years. It was efficient between 2012-2015, but in 2016 efficiency score dropped to $86.87 \%$. This decrease happened despite the reduced number of LC in UK from 6,617 in 2012 to 6117 in 2016. Decreased tonnes of good transported by railways in UK from 115,225 in 2012 to 78,549 in 2016 affected the efficiency scores. The decrease in the selected period was $31.83 \%$. This decrease in transporting goods can be partly explained by congestion of railway lines in the UK that was caused by the increases in passenger-km from 60,783 million 
passenger-km in 2012 to 68,010 million passenger-km in 2016 . The increase in million passenger-km was $11.89 \%$.

The average efficiency score of selected countries for the period 2012-2016 was 25.79\%. It is widely believed that the reduction of the number of LCs will reduce the accidents at LCs. Despite the substantial reduction in number of LC in Europe in the last ten years, the number of accidents is still high. In 2017, there was 209 people injured at LCs around Europe [25]. The lowest number of LCs per $100 \mathrm{~km}$ of railway line in 2016 was NL, BG and SE, but the efficiency scores for these countries were $37.05 \%, 4.31 \%$ and $24.65 \%$ respectively. NL and SE had efficiency scores slightly higher than the average of $22.02 \%$. The lowest average efficiency score in 2016, which was less than 5\%, was BG, HR, GR and RO. The highest number of LCs per $100 \mathrm{~km}$ in 2016 was SE, AT and CZ. The efficiency scores in these countries were $28.42 \%, 8.66 \%$ and $7.22 \%$ respectively. AT and CZ had efficiency scores substantially lower than the average, which was $22.02 \%$. It appears that the low number of LC per $100 \mathrm{~km}$ of railway line does not always have the huge impact on efficiency of railways in terms of accident risk. There is a need to look for other factors that can influence the efficiency scores. For this reason, there was selected seven factors that can also influence the efficiency scores.

\section{IBM SPSS ANALYSES}

To find the relationship between selected variables and efficiency of railways in term of accident risk the IBM Statistical Program for the Social Sciences (SPSS) analytic software was applied. Table 2 shows the descriptive statistics selected variables.

For variable "Number of cars per 1000 inhabitants", skewness value is negative that indicates a clustering of scores at the high end. Positive kurtosis values indicated that the values clustered in the centre with long thin tails. Kurtosis values below 0 indicated a distribution is relatively flat [26]. To analyse the relationship between selected variables it is needed to assess the normality of the distribution of scores. To find outliers, cases with values well above or well below most of the other cases [26] the boxplot was built.

To explore the relationship between "Efficiency of railways in term of accident risk" and selected variables the scatterplot was build. The scatterplot gives an indication that the variables have a linear or curvilinear relationship. Only linear relationship is suitable for correlation analysis [26].

The correlation analyses are performed in order to find the relationship between variables. Pearson correlation coefficient take values between -1 and +1 . The sign in front of the values indicates whether there is a positive or negative correlation. Negative sign indicated that as one variable increases the other decreases and positive sign indicated that if one variable increases the other increases too. The size of the absolute value provides an indication of the strength of the relationship. A perfect correlation of +1 or -1 means that the exact value of one variable can be found by knowing the value of the other variable. A correlation of 0 means that there is no relationship between selected variables [26].

Testing the Pearson correlation coefficient has been following a guideline [26] which states that the strength of the relationship is:

$$
\text { Small } \quad \mathrm{r}=.10 \text { to } .29 ; \quad \text { Medium } \quad \mathrm{r}=.30 \text { to } .49 ; \quad \text { Large } \quad \mathrm{r}=.50 \text { to } 1 \text {. }
$$

Positive skewness values indicated that scores clustered to the left at the low values [26].

Table 3 shows the relationship between efficiency of railways in term of accident risk with selected variables. The coefficient of determination shows how much variance is shared by two selected variables or how much overlap there is between two variables [26]. 


\begin{tabular}{|c|c|c|c|c|c|c|c|c|c|c|c|}
\hline$\sqrt[I]{\sim}$ & $\frac{\infty}{\sigma}$ & $\frac{\infty}{\sigma}$ & $\frac{\infty}{a}$ & $\frac{\infty}{a}$ & $\frac{\infty}{a}$ & $\frac{\infty}{\sigma}$ & $\frac{\infty}{\sigma}$ & $\frac{\infty}{\sigma}$ & $\begin{array}{l}\infty \\
\sigma \\
\sigma \\
\end{array}$ & $\frac{\infty}{\sigma}$ & 0 \\
\hline 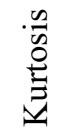 & $\begin{array}{l}\infty \\
\infty \\
\sim \\
+\end{array}$ & $\frac{d}{\stackrel{2}{r}}$ & $\begin{array}{l}\hat{\alpha} \\
\alpha \\
\infty\end{array}$ & 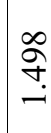 & $\left|\begin{array}{c}\vec{\delta} \\
\infty \\
\dot{0}\end{array}\right|$ & $\begin{array}{l}2 \\
\infty \\
\infty \\
i\end{array}$ & $\underset{n}{\sim}$ & $\stackrel{n}{n}$ & $\begin{array}{c}\vec{\infty} \\
\stackrel{1}{0} \\
0 \\
\end{array}$ & 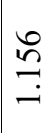 & $\hat{\varphi}$ \\
\hline 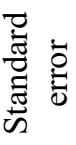 & 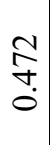 & 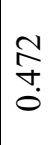 & 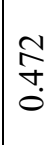 & 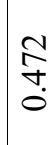 & 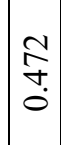 & 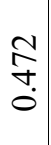 & 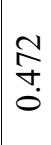 & 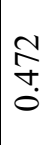 & $\begin{array}{c}\mathbb{N} \\
\stackrel{J}{t} \\
\dot{0}\end{array}$ & 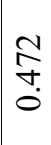 & 0 \\
\hline 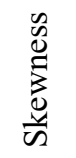 & $\frac{\nexists}{ \pm}$ & $\overrightarrow{\widetilde{\Omega}}$ & $\frac{8}{2}$ & İ & $\begin{array}{c}\vec{\sigma} \\
\sim \\
\sim\end{array}$ & 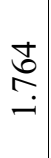 & 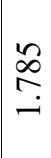 & $\begin{array}{l}\tilde{\alpha} \\
\tilde{n} \\
0\end{array}$ & $\begin{array}{l}\stackrel{0}{2} \\
\stackrel{0}{0}\end{array}$ & 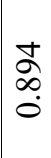 & $\begin{array}{l}\hat{\sigma} \\
n \\
o\end{array}$ \\
\hline 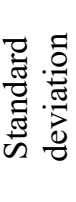 & 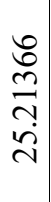 & 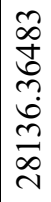 & 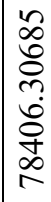 & 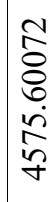 & 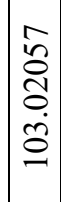 & $\begin{array}{l}0 \\
\infty \\
\infty \\
\infty \\
\vdots \\
\vec{\sim}\end{array}$ & 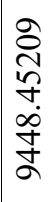 & 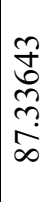 & $\mid \begin{array}{c}\infty \\
0 \\
\delta \\
6 \\
\dot{0} \\
\infty \\
\vec{J} \\
\vec{J}\end{array}$ & 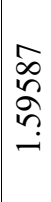 & $\frac{8}{8}$ \\
\hline 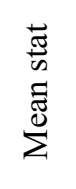 & 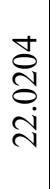 & $\begin{array}{l}8 \\
8 \\
0 \\
n \\
\infty \\
\infty \\
\infty \\
0\end{array}$ & 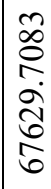 & $\begin{array}{l}\frac{1}{2} \\
\frac{1}{2} \\
i \\
\frac{n}{8}\end{array}$ & 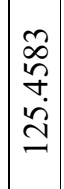 & $\begin{array}{l}8 \\
\stackrel{\circ}{\curvearrowleft} \\
\stackrel{2}{=}\end{array}$ & $\begin{array}{l}\tilde{\infty} \\
\tilde{n} \\
\dot{n} \\
\tilde{N} \\
\tilde{\delta} \\
\delta\end{array}$ & \begin{tabular}{l}
8 \\
8 \\
$\frac{0}{7}$ \\
\multirow{1}{*}{}
\end{tabular} & 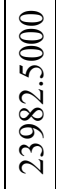 & $\begin{array}{l}\frac{n}{n} \\
\stackrel{\gamma}{\gamma}\end{array}$ & 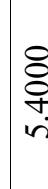 \\
\hline $\begin{array}{l}\overrightarrow{\tilde{J}} \\
\tilde{W} \\
\dot{x} \\
\tilde{\Xi}\end{array}$ & $\begin{array}{l}8 \\
8 \\
8\end{array}$ & $\begin{array}{c}8 \\
8 \\
6 \\
0 \\
\dot{1} \\
2 \\
a\end{array}$ & 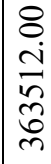 & $\begin{array}{l}8 \\
0 \\
\infty \\
6 \\
0 \\
0\end{array}$ & $\left|\begin{array}{c}0 \\
= \\
\infty \\
\stackrel{+}{q} \\
\mid\end{array}\right|$ & $\begin{array}{l}8 \\
\stackrel{\infty}{\infty} \\
\end{array}$ & 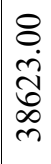 & $\begin{array}{l}8 \\
\text { î } \\
6\end{array}$ & 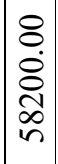 & 年 & ळ. \\
\hline 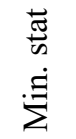 & $\begin{array}{l}n \\
n \\
m\end{array}$ & $\begin{array}{l}8 \\
8 \\
\dot{0} \\
\sim \\
\sim\end{array}$ & $\begin{array}{l}8 \\
8 \\
\dot{d} \\
\stackrel{8}{0}\end{array}$ & $\begin{array}{l}8 \\
\stackrel{8}{i} \\
\underset{\sim}{2}\end{array}$ & $\mid \begin{array}{c}0 \\
\dot{\infty} \\
-\end{array}$ & $\underset{-}{8}$ & 送 & o & $\mid \begin{array}{l}8 \\
\dot{0} \\
0 \\
0 \\
0\end{array}$ & 号 & $\begin{array}{l}0 \\
0\end{array}$ \\
\hline$\stackrel{0}{z}$ & $\stackrel{\sim}{\sim}$ & $\stackrel{\sim}{\sim}$ & $\stackrel{\Xi}{\sim}$ & $\stackrel{ \pm}{\sim}$ & $\stackrel{\Xi}{\sim}$ & $\stackrel{\Xi}{\sim}$ & $\stackrel{\sim}{\sim}$ & $\stackrel{\Xi}{\sim}$ & $\stackrel{ \pm}{\sim}$ & $\stackrel{\sim}{\sim}$ & $\stackrel{\Xi}{\sim}$ \\
\hline$\frac{\frac{0}{0}}{\frac{\pi}{\pi}}$ & 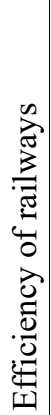 & 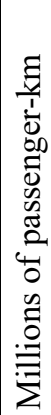 & 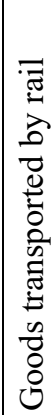 & 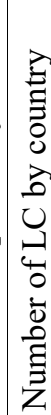 & 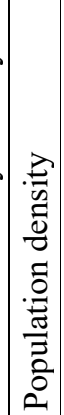 & 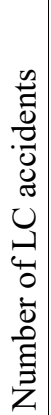 & 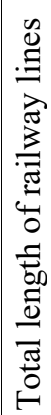 & 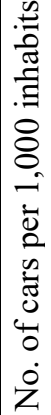 & 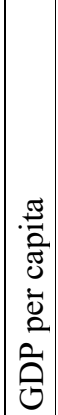 & 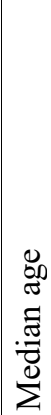 & $\begin{array}{l}\tilde{\pi} \\
\mathcal{Z} \\
\mathcal{Z} \\
\mathcal{2}\end{array}$ \\
\hline
\end{tabular}


Table 3: Summary of Pearson correlation test. (Source: Author's creation.)

\begin{tabular}{|l|l|c|c|c|}
\hline & Variables & $\begin{array}{c}\text { Pearson } \\
\text { correlation } \\
\text { coefficient }\end{array}$ & $\begin{array}{c}\text { Interpretation } \\
\text { of relationship }\end{array}$ & $\begin{array}{c}\text { Coefficient of } \\
\text { determination } \\
(\%)\end{array}$ \\
\cline { 2 - 5 } $\begin{array}{l}\text { Efficiency of } \\
\text { railways in term } \\
\text { of accident risk } \\
\text { at LC }\end{array}$ & $\begin{array}{l}\text { Number of LC by } \\
\text { country }\end{array}$ & -0.29 & weak & 8.41 \\
\cline { 2 - 5 } & Population density & 0.427 & moderate & 18.23 \\
\cline { 2 - 5 } & Road accidents & -0.352 & moderate & 12.39 \\
\cline { 2 - 5 } & GDP per capita & 0.538 & strong & 28.94 \\
\hline
\end{tabular}

\section{DISCUSSION AND ANALYSES}

The key factors affecting the efficiency of railways in term of accident risk are:

\subsection{Factor 1 - Number of LCs in a country}

The number of LCs in a country has a negative weak relationship with efficiency of railways in term of accident risk at LC. This means that increasing the number of LCs decreases the efficiency of railways in terms of accident risk at LCs. To improve the efficiency of railways in terms of accident risk at LCs, there is a need to work on a reduction of the number of LCs where it is economically viable. Countries such as France (16678), Germany (14054) and Poland (13109) have the highest number of LCs, but the efficiency of railways in term of accident risk at LC is quite low as France has $20.58 \%$, Germany $16.74 \%$ and Poland $7.54 \%$.

\subsection{Factor 2 - Population density}

Population density has a positive moderate relationship with efficiency of railways in term of accident risk at a LC. The increases of population increase the efficiency of railways in terms of accident risk at LC. In countries with a higher density of population, there is an observed higher efficiency of railways in term of accident risk at LC. Regarding railways in countries with a higher density of population, improving safety at LCs requires more radical measures. From five countries (NL, IT, GB, CH and DE) with the highest level of density of population in Europe, four countries (NL, IT, GB and CH) scored the highest efficiency of railways in term of accident risk at LCs score. The score of efficiency of railways in term of accident risk at LC for 2016 was $37.05 \%, 40.65 \%, 86.87 \%$ and $100 \%$ respectively. Only DE has lower score of $16.74 \%$.

\subsection{Factor 3 - Number of deaths per 100,000 people in road accidents in 2016}

The number of deaths has a negative moderate relationship with efficiency of railways in terms of accident risk at a LC. The increasing number of deaths in road accidents decreases the efficiency of railways. 


\subsection{Factor 4 - GDP per capita}

GDP per capita has strong positive relationship with efficiency of railways in term of accident risk at LC. This means that, countries with a higher GDP per capita observed higher efficiency of railways in term of accident risk at LC score. This means that railways authorities in countries with a stronger economy invest more money to eliminate accident risk at LCs. Countries with the highest GDP per capita in 2016 of the selected ones in this study are $\mathrm{CH}, \mathrm{DK}, \mathrm{SE}, \mathrm{NL}, \mathrm{AT}, \mathrm{FI}, \mathrm{DE}, \mathrm{FR}$ and GB. Five from them have the highest score of efficiency of railways in term of accident risk at LC for 2016. They are CH, GB, IT, NL and SE.

\section{CONCLUSIONS}

Railways around the world have benefited from the continuing improvement in the control and communication systems, but LCs remain a substantial safety risk. The LC is regarded as the largest single risk element of train accidents. The consequences of each accident are not limited to the loss of life but also the damage to the infrastructure and rolling stock, traffic disruption and damage to the reputation of the rail travel as a safe mode of transportation. To reduce the number of accidents at LCs, there is a need to close them where it is necessary to do so and to improve the related risk mitigation measures. Closing LCs, replacing them with bridges or underpasses have an economic benefit for both railways and for local communities. Uninterrupted road traffic flow can reduce the congestion, delays, air and noise pollution and overall make the transport system more sustainable. Railways can benefit from reducing LC maintenance and operational costs. It reduces the number employees, improves the speed and reliability of trains and increases the line capacity. Eliminating a LC can be cost-effective but upgrading the LC very often can be expensive and not proportional to the risk reduction that was achieved.

It was found that many factors can influence the efficiency of railways in term of accident risk. In this research, a number of factors were selected to investigate their relationship with efficiency scores, and it was found that the strongest relationship with efficiency scores have a number of LCs in a country, population density and GDP per capita.

From the results of this investigation, conclusions can be made that when evaluating the safety at LCs specific railways there is a need to take into consideration the level of economic development and density of population in the country. For some railways, improving the safety level at LCs is easier than for others where stagnation in economy and low density of population negatively affect performance of railways. There is an exception for this, the Baltic State countries [27]. GDP per capita in Euro in 2016 in LV was $€ 11030$, LT was $€ 12,040$ and in EE was $€ 13650$. Nevertheless, LV has $46.99 \%$ efficiency score, the third highest score of efficiency of railways in terms of accident risk at LC after $\mathrm{CH}$ with $100 \%$ and GB with $86.87 \%$. This can be explained by the low number of passenger cars on the roads and by low railway traffic. In $2016 \mathrm{LV}$ had one of the lowest numbers of passenger cars per 1000 inhabitants 341 cars. Romania had 261 and Hungary had 338 cars per 1000 inhabitant. Also, LV had low passenger traffic by railway and goods transported by rail which was only 47819 million tonnes which was lower than the average which was 67629 million tonnes.

To reduce the number of accidents, it is a need to better understand the local and human factors. It is crucial to increase the number of awareness campaigns and improves the cooperation between different road and railway institutions and stakeholders. Although, technology is fundamental to improving the safety at LCs, but safety can also be improved by educating the public and by enforcing related laws and regulations. 


\section{REFERENCES}

[1] Djordjević, B., Krmac, E. \& Mlinarić, T., Non-radial DEA model: A new approach to evaluation of safety at railway level crossings. Safety Science, 103, pp. 234-246, 2018.

[2] Nguyen-Phuoc, D., Currie, G., De Gruyter, C. \& Young, W., New method to estimate local and system-wide effects of level rail crossings on network traffic flow. Journal of Transport Geography, 60, pp. 89-97, 2017.

[3] Larue, G., Filtness, A., Wood, J., Demmel, S., Watling, C., Naweed, A. \& Rakotonirainy, A., Is it safe to cross? Identification of trains and their approach speed at level crossings. Safety Science, 103, pp. 33-42, 2018.

[4] Laapotti, S., Comparison of fatal motor vehicle accidents at passive and active railway level crossings in Finland. IATSS Research, 40(1), pp. 1-6, 2016.

[5] ERA, Level crossings safety in the European Union 2012a. www.era.europa.eu/ Document-Register/Documents/Level_crossing_safety_EU_2012.pdf. Accessed on: 9 Jan. 2018.

[6] Raib, Fatal accident at Halkirk level crossing - GOV.UK 2009. www.raib.gov.uk/ publications/investigation_reports/reports_2010/report162010.cfm. Accessed on: 9 Jan. 2018.

[7] Pacts, Safety at level crossings: PACTS submission to the Transport Select Committee 2013. www.pacts.org.uk/wp-content/uploads/sites/2/Safety-at-Level-CrossingsPACTS-submitted.pdf. Accessed on: 9 Jan. 2018.

[8] ERA, Railway safety performance in the European Union, 2016. www.era.europa.eu/Document-Register/Documents/Railway\%20Safety\%20

Performance\%202016\%20final\%20E.pdf. Accessed on: 9 Jan. 2018.

[9] European Commission (EC), Road safety in European Union, trends, statistics and main challenges, 2015. https://ec.europa.eu/transport/sites/transport/files/road_safety/ pdf/vademecum_2015.pdf. Accessed on: 9 Jan. 2018.

[10] EC, File: Number of persons killed and injured by type of accident and category of persons in EU-28, 2014 final.png - Statistics Explained, 2017. http://ec.europa.eu/ eurostat/statistics-explained/index.php/File:Number_of_persons_killed_and_injured_ by type_of_accident and category_of_persons_in_EU-28,2014_final.png.

Accessed on: 9 Jan. 2018.

[11] Arrivealive, Level crossing safety supplement, 2012. www.arrivealive.co.za/ documents/Level-Crossing-Safety-Supplement-2012.pdf. Accessed on: 9 Jan. 2018.

[12] Theaa, Level crossing safety, AA, 2011. www.theaa.com/motoring_advice/news/ level-crossing-safety-more-drivers-playing-russian-roulette.html. Accessed on: 9 Jan. 2018.

[13] ERA, Railway safety performance in the European Union, 2012. www.era.europa.eu/ Document-Register/Documents/SafetyReport2012.pdf. Accessed on: 9 Jan. 2018.

[14] Global Railway Review, Level crossing safety in-depth focus, 2017. www.globalrailwayreview.com/article/33865/level-crossing-strategy-in-depth-focus2017/. Accessed on: 9 Jan. 2018.

[15] Bahloul, K., Defossez, F., Ghazel, M. \& Collart-Dutilleul, S., Adding technological solutions for safety improvement at level crossings: A functional specification. Procedia - Social and Behavioral Sciences, 48, pp. 1375-1384, 2012.

[16] Liang, C., Ghazel, M., Cazier, O. \& El-Koursi, E., A new insight on the risky behavior of motorists at railway level crossings: An observational field study. Accident Analysis \& Prevention, 108, pp. 181-188, 2017. 
[17] Freeman, J. \& Rakotonirainy, A., Mistakes or deliberate violations? A study into the origins of rule breaking at pedestrian train crossings. Accident Analysis and Prevention, 77, pp. 45-50, 2015.

[18] Rudin-Brown, C., Lenné, M., Edquist, J. \& Navarro, J., Effectiveness of traffic light vs. boom barrier controls at road-rail level crossings: A simulator study. Accident Analysis and Prevention, 45, pp. 187-194, 2012.

[19] Beanland, V., Salmon, P., Filtness, A., Lenné, M. \& Stanton, N., To stop or not to stop: Contrasting compliant and non-compliant driver behaviour at rural rail level crossings. Accident Analysis \& Prevention, 108, pp. 209-219, 2017.

[20] Tey, L., Wallis, G., Cloete, S. \& Ferreira, L., Modelling driver behaviour towards innovative warning devices at railway level crossings. Accident Analysis and Prevention, 51, pp. 104-111, 2013.

[21] Kelly, J., The level crossing wars 2014. BBC News. www.bbc.co.uk/news/magazine27037582. Accessed on: 9 Jan. 2018.

[22] Lo, C., SafeRail level crossing study: putting ideas into action - Railway Technology 2015. www.railway-technology.com/features/featuresaferail-level-crossing-studyputting-ideas-into-action-4526758/. Accessed on: 10 Jan. 2018.

[23] Nataraja, N. \& Johnson, A., Guidelines for using variable selection techniques in data envelopment analysis. European Journal of Operational Research, 215(3), pp. 662669, 2011.

[24] Yu, M., Assessing the technical efficiency, service effectiveness, and technical effectiveness of the world's railways through NDEA analysis. Transportation Research Part A: Policy and Practice, 42(10), pp. 1283-1294, 2008.

[25] EC, Rail accident fatalities in the EU - Statistics Explained 2020. https://ec.europa.eu/ eurostat/statistics-explained/index.php/Rail_accident_fatalities_in_the_EU. Accessed on: 4 Jan. 2020.

[26] Pallant, J., SPSS Survival Mannual, 1st ed., McGraw-Hill: London, pp. 59-77, 2013.

[27] Watson I., Ali A. \& Bayyati A., Sustainability of HSR-comparative study. ICE Innovation in Railway Civil Engineering Journal, 2019. www.icevirtuallibrary.com/ doi/pdf/10.1680/jtran.18.00131. 